\title{
EPIDEMIOLOGICAL ANALYSIS OF THE DISTRIBUTION OF MAMMOGRAPHY PERFORMED IN GOIÁS, MATO GROSSO, MATO GROSSO DO SUL AND FEDERAL DISTRICT FROM 2010 TO 2013
}

Paula de O. C. Queiroz¹, Giselle M. Guimarães¹, Murilo H. C. e Silva¹, Isadora R. Silva1, Túlio P. A. Basílio¹, Laine R.Martins ${ }^{1}$

${ }^{1}$ Universidade Federal de Goiás - Goiânia (GO), Brazil.

Objective: To evaluate the spatial distribution of mammograms performed in the central-west region, comparing the results obtained from the State of Goiás to the other States of the region (Mato Grosso, Mato Grosso do Sul and Federal District). Methodology: This is a descriptive study, quantitative analysis, based on data collected from any mammography type, from January 2010 to December 2013, available in the Breast Cancer Information System (SISCAM) of the Ministry of Health. Results: Organizing into categories, the Federal District was the state that most increased the number of mammograms in absolute and relative numbers compared to the states of the center-west region. This data is very relevant, since it indicates a greater coverage of the health system and investment when compared with the others. In addition, a very important indicator is the capital/state ratio since it shows whether the coverage of mammograms is concentrated only in the metropolitan region or if it can give access to a large part of the population of the state in a uniform way. Mato Grosso is the state with the largest distribution of mammography coverage, compared to Goiás and Mato Grosso do Sul. Only 33.54\% of mammograms were performed in the capital of Mato Grosso, while in Goiás (56.53\%) and in Mato Grosso do Sul (51.79\%) in their respective capitals. It should be noted that the study period was from 2010 to 2013, during which data were collected. Conclusion: The results show significant growth of mammograms performed in the center-west region. This shows that coverage and access to this exam is being expanded. However, it also shows that the central regions performs larger numbers of mammograms in relation to the other regions of the states. This corroborates to an unequal coverage estimate for the population of the states. In addition to making access difficult due to patient locomotion problems to go to the capitals / central regions to perform the exams, this concentration of exams in the metropolitan regions can cause a crowding in the services, making access to the breast cancer screening even more difficult. 